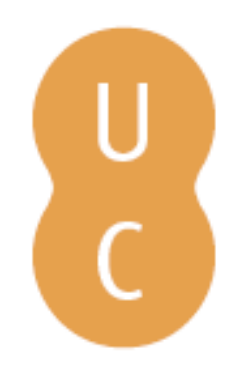

\title{
pompalina
}

\section{Teofrasto, Tratado das plantas: no alvor de uma nova ciência}

Autor(es): $\quad$ Silva, Maria de Fátima

Publicado por: UA Editora - Universidade de Aveiro; Imprensa da Universidade de

URL

persistente: URI:http://hdl.handle.net/10316.2/35687

DOI: $\quad$ DOI:http://dx.doi.org/10.14195/978-989-26-0941-6_1

Accessed : $\quad$ 26-Apr-2023 12:22:15

A navegação consulta e descarregamento dos títulos inseridos nas Bibliotecas Digitais UC Digitalis, UC Pombalina e UC Impactum, pressupõem a aceitação plena e sem reservas dos Termos e Condições de Uso destas Bibliotecas Digitais, disponíveis em https://digitalis.uc.pt/pt-pt/termos.

Conforme exposto nos referidos Termos e Condições de Uso, o descarregamento de títulos de acesso restrito requer uma licença válida de autorização devendo o utilizador aceder ao(s) documento(s) a partir de um endereço de IP da instituição detentora da supramencionada licença.

Ao utilizador é apenas permitido o descarregamento para uso pessoal, pelo que o emprego do(s) título(s) descarregado(s) para outro fim, designadamente comercial, carece de autorização do respetivo autor ou editor da obra.

Na medida em que todas as obras da UC Digitalis se encontram protegidas pelo Código do Direito de Autor e Direitos Conexos e demais legislação aplicável, toda a cópia, parcial ou total, deste documento, nos casos em que é legalmente admitida, deverá conter ou fazer-se acompanhar por este aviso.

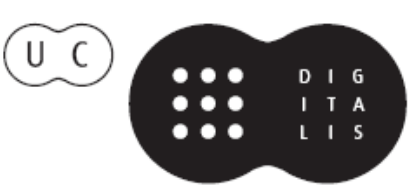




\section{HUMANISMO E CIÊNCIA Antiguidade e Renascimento}

António Manuel Lopes Andrade

Carlos de Miguel Mora

João Manuel Nunes Torrão
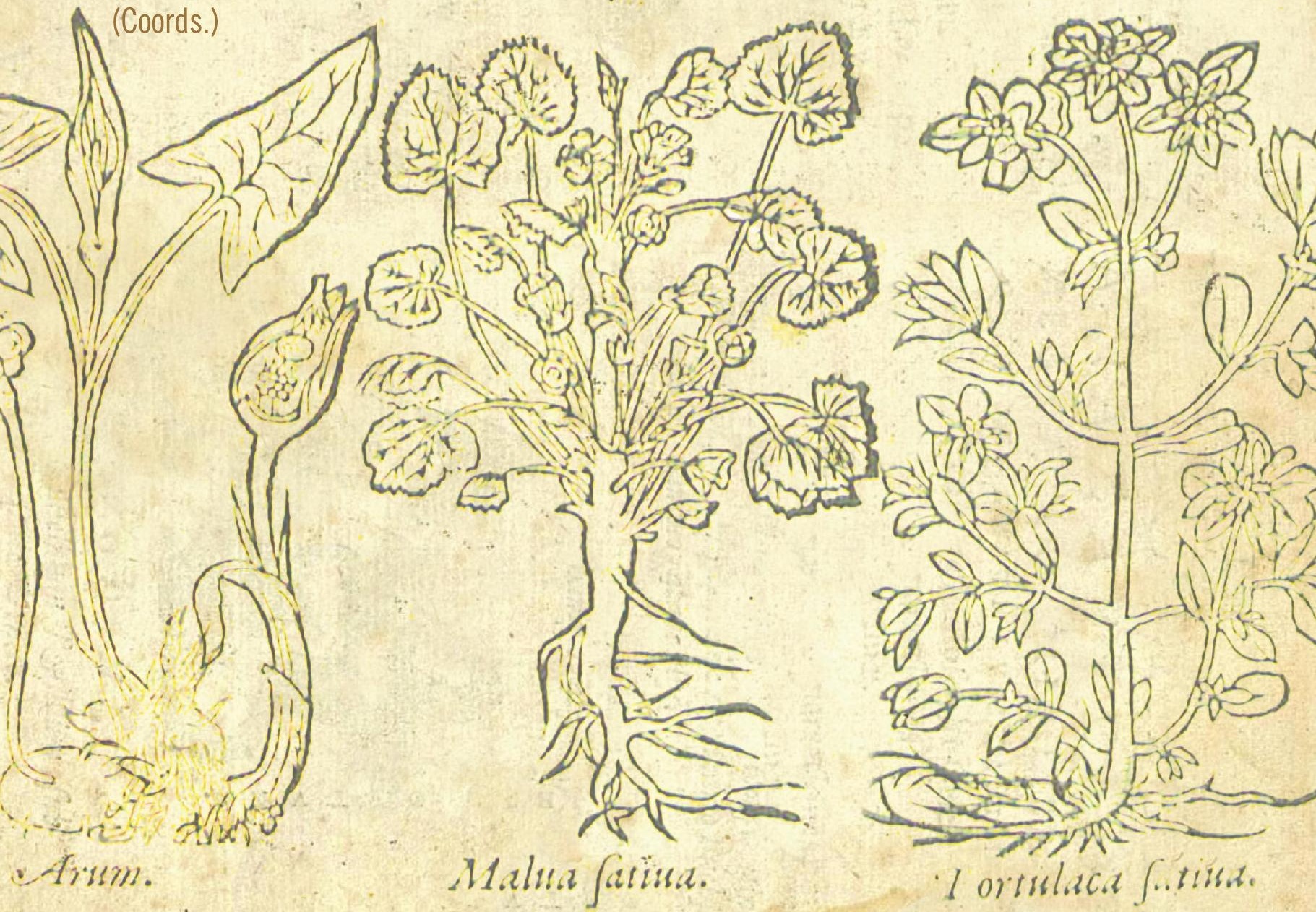

Aveiro I Coimbra I São Paulo 2015

UA Editora - Universidade de Aveiro I Imprensa da Universidade de Coimbra I Annablume 
Este volume resulta de várias iniciativas desenvolvidas no âmbito do projecto de I\&D "Dioscórides e o Humanismo Português: os Comentários de Amato Lusitano" (http://amatolusitano.web.ua.pt), recoIhendo contribuições de mais de duas dezenas de colaboradores, tanto de membros da equipa como de outros investigadores nacionais e estrangeiros. Entre os eventos que estiveram na origem deste livro destacam-se as três edições do Ciclo de Conferências promovido pelo projecto, realizadas entre 2010 e 2013, e sobretudo o Colóquio Internacional "Dioscórides e o Humanismo Português: os Comentários de Amato Lusitano", que decorreu no Departamento de Línguas e Culturas da Universidade de Aveiro, nos dias 21 e 22 de Novembro de 2013.

0 objectivo principal do projecto é a edição e tradução para português dos dois livros que Amato Lusitano dedicou ao comentário do tratado grego De materia medica de Dioscórides, ou seja, o Index Dioscoridis (Antuérpia, 1536) e as In Dioscoridlis Anazarbei de medica materia libros quinque... enarrationes (Veneza, 1553), estando contemplada, também, a tradução de mais duas obras directamente correlacionadas com os livros do médico português: a montante, a do próprio tratado grego de Dioscórides; a jusante, a do livro intitulado Apologia adversus Amathum Lusitanum (Veneza, 1558) de Pietro Andrea Mattioli.

OBRA PUBLICADA COM A COORDENAÇÃO

CIENTÍFICA DE:

Centro de Línguas, Literaturas e Culturas da Universidade de Aveiro

Centro de Estudos Clássicos e Humanísticos da Universidade de Coimbra

Cátedra de Estudos Sefarditas "Alberto

Benveniste" da Faculdade de Letras da Universidade de Lisboa 


\section{HUMANISMO E CIÊNCIA}

\section{Antiguidade e Renascimento}

ANTÓNIO MANUEL LOPES ANDRADE

CARLOS DE MIGUEL MORA

JOÃO MANUEL NUNES TORRÃO

(COORDS.)

AVEIRO • COIMBRA • SÃO PAULO

2015

UA EDITORA • UNIVERSIDADE DE AVEIRO

IMPRENSA DA UNIVERSIDADE DE COIMBRA

ANNABLUME 


\section{HUMANISMO E CIÊNCIA: Antiguidade e Renascimento}

\author{
EDIÇÃO

UA EDITORA • UNIVERSIDADE DE AVEIRO
IMPRENSA DA UNIVERSIDADE DE COIMBRA
ANNABLUME

ORGANIZAÇÃO E COORDENAÇÃO EDITORIAL ANTÓNIO MANUEL LOPES ANDRADE

CARLOS DE MIGUEL MORA

JOÃO MANUEL NUNES TORRÃO

\author{
DESIGN DA CAPA \\ MEIOKILO DESIGN STUDIO
}

DESIGN

CARLOS COSTA

IMPRESSÃO E ACABAMENTO

SERSILITO • MAIA

ISBN

UA • 978-972-789-434-5

IUC • 978-989-26-0940-9

\section{ISBN DIGITAL}

UA • 978-972-789-435-2

IUC • 978-989-26-0941-6

DOI

http://dx.doi.org/10.14195/ 978-989-26-0941-6

DEPÓSITO LEGAL 368241/13

TIRAGEM 500 Exemplares

(C) 2015

UA EDITORA • UNIVERSIDADE DE AVEIRO IMPRENSA DA UNIVERSIDADE DE COIMBRA

ANNABLUME

\section{COMISSÃO CIENTÍFICA}

António Manuel Lopes Andrade

Carlos de Miguel Mora

Delfim Ferreira Leão

Henrique Leitão

João Manuel Nunes Torrão

Maria de Fátima Reis

Maria do Céu Zambujo Fialho

Miguel Ángel González Manjarrés

\section{TEXTOS}

Adelino Cardoso

Ana Leonor Pereira

Ana Margarida Borges

António Guimarães Pinto

António Maria Martins Melo

Bernardo Mota

Carlos A. Martins de Jesus

Carlos de Miguel Mora

Cristina Santos Pinheiro

Donald Beecher

Emília Oliveira

Isabel Malaquias

James W. Nelson Novoa

Joana Mestre Costa

João Manuel Nunes Torrão

João Rui Pita

Jorge Paiva

José Sílvio Moreira Fernandes

Maria de Fátima Silva

Miguel Ángel González Manjarrés

Rui Manuel Loureiro

Telmo Corujo dos Reis

Teresa Nobre de Carvalho

Vinicije B. Lupis

Virgínia Soares Pereira 


\section{HUMANISMO E CIÊNCIA}

\section{Antiguidade e Renascimento}

ANTÓNIO MANUEL LOPES ANDRADE

CARLOS DE MIGUEL MORA

JOÃO MANUEL NUNES TORRÃO

(COORDS.)

AVEIRO • COIMBRA • SÃO PAULO

2015

UA EDITORA • UNIVERSIDADE DE AVEIRO

IMPRENSA DA UNIVERSIDADE DE COIMBRA

ANNABLUME 
OBRA PUBLICADA

COM A COORDENAÇÃO

CIENTÍFICA DE:

CENTRO DE LÍNGUAS,

LITERATURAS E CULTURAS DA

UNIVERSIDADE DE AVEIRO

CENTRO DE ESTUDOS

CLÁSSICOS E HUMANÍSTICOS DA

UNIVERSIDADE DE COIMBRA

CÁTEDRA DE ESTUDOS SEFARDITAS

"ALBERTO BENVENISTE"

DA FACULDADE DE LETRAS DA

UNIVERSIDADE DE LISBOA 


\section{SUMÁRIO}

PREFÁCIO

1.1 "Teofrasto, Tratado das plantas. No alvor de uma nova ciência" 13

Maria de Fátima Silva

1.2 "Francisco de Melo e os fragmentos de teoria óptica de Pierre Brissot" 21 Bernardo Mota

1.3 "Algumas reflexões sobre as pedras preciosas nos Colóquios dos simples de Garcia de Orta" 37 Rui Manuel Loureiro

1.4 "Estratégias, patronos e favores em Colóquios dos Simples de Garcia de Orta" 63 Teresa Nobre de Carvalho

1.5 "As plantas na obra poética de Camões (épica e lírica)" 95 Jorge Paiva

1.6 "Nicolás Monardes, John Frampton and the Medical Wonders of the New World" .141 Donald Beecher

1.7 "Literatura e Medicina: alguns textos de Justo Lípsio e de dois doutores Luís Nunes" 161 António Guimarães Pinto

1.8 "Ontologias e idiossincrasias dos Amantes, à luz da Archipathologia de Filipe Montalto" ...... 211 Joana Mestre Costa \& Adelino Cardoso

1.9 "Gabriel da Fonseca. A New Christian doctor in Bernini's Rome". .227 James W. Nelson Novoa 


\section{2) DIOSCÓRIDES E O HUMANISMO PORTUGUÊS: OS COMENTÁRIOS DE AMATO LUSITANO}

2.1 "Léxico científico português nos Comentários de Amato: antecedentes e receção"

Ana Margarida Borges

2.2 "Usos medicinais das plantas, em Amato Lusitano: o bálsamo"

António Maria Martins Melo

2.3 "Amato Lusitano e a importância da ilustração botânica no século xVI.

Em torno das edições lionesas das Enarrationes (1558)"

Carlos A. Martins de Jesus

2.4 "Sobre la identificación entre ébano y guayaco en una entrada

del Index Dioscoridis de Amato Lusitano".

Carlos de Miguel Mora

2.5 "Os partos distócicos em Amato Lusitano e em Rodrigo de Castro:

fontes, doutrinas e terapias greco-romanas"

\section{Cristina Santos Pinheiro}

2.6 "Do carvalho ao castanheiro: usos e propriedades medicinais

de fagáceas nas Enarrationes de Amato Lusitano".

Emília Oliveira

2.7 "O mundo mineral nos Comentários a Dioscórides de Amato Lusitano".

Isabel Malaquias \& Virgínia Soares Pereira

2.8 "Alguns comentários de Amato: entre a estranheza e a realidade"

João Manuel Nunes Torrão

2.9 "Caracterização e usos terapêuticos de produtos de origem marinha

nos Comentários de Amato Lusitano a Dioscórides"

José Sílvio Moreira Fernandes

2.10 "La mandrágora de Amato Lusitano: edición, traducción y anotación"

Miguel Ángel González Manjarrés

2.11 "O vinho e os vinhos - usos e virtudes de um dom dos deuses

nas Enarrationes de Amato Lusitano"

Telmo Corujo dos Reis

2.12 "Amatus Lusitanus e Didaco Pirro: due ebrei portoghesi

e cerchia umanistica di Dubrovnik" 481

Vinicije B. Lupis

2.13 "Estudos contemporâneos sobre Amato Lusitano". 513

João Rui Pita \& Ana Leonor Pereira 


\section{Teofrasto, Tratado das plantas. No alvor de uma nova ciência}

MARIA DE FÁTIMA SILVA ${ }^{1}$

\section{RESUMO:}

Ao propor-se a abordagem de uma nova ciência - a Botânica — Teofrasto pondera também a metodologia a seguir e a definição de uma terminologia técnica adequada. Para responder a estas questões, serve-se da experiência colhida já numa ciência paralela - a Biologia - , com a qual convivia dentro da escola de Aristóteles. Apesar de encontrar nessa aproximação sugestões úteis, Teofrasto nunca deixa de afirmar as diferenças que distinguem os dois objectos de estudo, animais e plantas.

\section{PALAVRAS-CHAVE:}

metodologia; terminologia; partes; peripatéticos.

\section{ABSTRACT:}

On approaching a new science - Botanic - Theophrastus reflects on methodology and a specific terminology to be used. The experience of a parallel science - Biology - , quite well known in the Lyceum, is clearly useful. Although being conscious about similarities between the two sciences, Theophrastus also recognizes differences between the object of each of them, animals and plants.

KEYWORDS:

methodology; terminology; parts; peripatetic school.

1 Centro de Estudos Clássicos e Humanísticos da Universidade de Coimbra: fanp@fl.uc.pt. 
Porque se trata do arranque para uma ciência inovadora ${ }^{2}$, o Tratado das plantas abre com uma reflexão sobre o que parece a Teofrasto essencial nos objectivos a atingir e na metodologia a praticar ${ }^{3}$. Ora justamente as questóes metodológicas, conformes com as praticadas entre os peripatéticos e que estão na base das colocadas pela ciência através do tempo ${ }^{4}$, constituem um dos aspectos mais atractivos no estudo dos tratados científicos legados pela Antiguidade, apesar de todas as dúvidas ou limitaçóes que a definição de uma metodologia deixa de pé. No Tratado das plantas esta é matéria que ocupa o Livro I e os primeiros capítulos do II (1-4).

O Liceu e o seu mestre fundador, Aristóteles, proporcionaram a Teofrasto um modelo natural: o estudo de um outro grupo de seres vivos, os animais, a que haviam sido já dedicados tratados abrangentes, A História dos animais - que enumera e descreve os animais e tenta uma classificação através do estabelecimento de semelhanças e diferenças entre os diversos grupos - e As Partes dos animais - que avança para um estudo mais específico, procurando identificar as partes e a sua utilidade para a vida de cada espécie 5 . Nessa investigação, levada a cabo por Aristóteles, o próprio Teofrasto terá tido uma intervenção directa. Não há dúvida de que as remissóes para esses dois tratados aristotélicos são numerosas no Tratado das plantas, do mesmo modo que é constante a preocupação de estabelecer contrastes entre o raciocínio que funciona no estudo dos animais, mas não no das espécies vegetais (1.3): 'Não se deve estabelecer uma correspondência total com os animais, nem no que se refere à reprodução, nem sob outro qualquer ponto de vista'.

Teofrasto acentua e especifica, entre animais e plantas, as divergências sob perspectivas encaradas em paralelo - ou seja, a partir de ciência feita, procede por sucessivas comparações: se, por exemplo, os frutos de uma planta podem ser considerados 'partes', as crias dos animais

2 Apesar de já ter havido, em época anterior, algumas abordagens das questões suscitadas pelas plantas - nos tratados hipocráticos, ou por nomes avulso de interessados pelo poder curativo das plantas, como Díocles de Caristo, por exemplo - tem sido reconhecido a Teofrasto o mérito de ter dado os primeiros passos no sentido de fazer do estudo das plantas uma verdadeira ciência e, nessa medida, ser o verdadeiro criador da Botânica.

3 Diógenes LAÉRCIO 5. 42-50 atribui a Teofrasto dois tratados dedicados às plantas; além daquele em que se centra este estudo (em 9 livros), também o intitulado Causas das plantas (em 6 livros), voltado para questões de morfologia e fisiologia. Aristóteles teria já avançado com algumas considerações elementares nesta matéria; por um lado, são frequentes as observações comparativas entre animais e plantas nos estudos que o Estagirita dedicou à biologia; vide Costas A. Thanos, "Aristotle and Theophrastus on plant-animal interactions", in Margarita ARIANOUTSOU and Richard H. GROVES, Plant-Animal Interactions in Mediterranean-Type Ecosystems. Dordrecht/Boston/London, Kluwer Academic Publishers, 1994, pp. 3-11; e num estudo em dois livros Sobre as plantas, de autoria controversa, que seria uma tentativa de classificação das espécies. Teofrasto teria levado esta abordagem bastante mais longe.

4 O mérito que Wolfgang KullmanN, "Aristotle as a natural scientist", Acta Classica 34 (1991), p. 137. atribui a Aristóteles - 'o de ter validado, com suporte teórico, a fundação das ciências' — seria oportuno também para Teofrasto, na perspectiva das plantas em particular, dada a estreita colaboração que ambos partilharam.

5 O próprio TEOFRASTO foi autor de um tratado de biologia, Sobre os animais, em sete livros, referido também por Diógenes LAÉRCIO 5.44. 
não; uns e outros têm partes caducas (no animal, cornos, penas e pêlos, HA 600a 15-16); mas, sob o ponto de vista da reprodução, o fruto desvincula-se por completo da planta, enquanto, nos animais, há produtos que prevalecem para além da gestação (o leite, a placenta, por exemplo); a reprodução animal tende à propagação da espécie, enquanto a planta se desenvolve toda ela ao longo da sua existência ${ }^{6}$; logo as flores, folhas e frutos poderiam ser partes, as crias não' (1.3).

Ponderadas estas diversas razóes, pode Teofrasto concluir pelas limitações deste método comparativo entendido sistematicamente, quando estão em causa seres tão diferentes (1.4): 'É pura perda de tempo empenharmo-nos em estabelecer comparações impossíveis, acabando por nos desviarmos do nosso objecto de estudo'. Mesmo assim, embora forçado a encontrar para a Botânica uma índole científica própria, face às características do seu objecto de estudo, a comparação nunca é posta de lado pelas comodidades que oferece apesar de todas as suas limitaçôes. Como nota Jacques Desautels ${ }^{7}$, 'o propósito de Teofrasto assenta numa investigação em que não só as conclusões mas também a própria metodologia estão em progresso'.

Parece inevitável considerar a observação como a primeira técnica a pôr em prática; um tratado científico credível tem de assentar na recolha de dados, sua comparação e análise. Antes de satisfeitas as regras da historia, ou seja, a recolha de testemunhos directos e a sua avaliação, não há condições para definir e tratar qualquer objecto de estudo. A seguir, a classificação é, para o Tratado das plantas, a questão de fundo: o que distingue uma planta de outra, ou seja, a possibilidade de estabelecer uma classificação por critérios de semelhança ou diferença entre elas e o que constitui a natureza própria de cada uma perante as demais; logo, a comparação entre os diversos seres que constituem um mesmo género e o confronto com géneros equivalentes está no cerne da proposta. A relação entre 'o mais e o menos' é usada como um critério decisivo no estabelecimento de semelhanças ou diferenças morfológicas. A História dos animais é, para este propósito, o modelo directo.

Embora reconhecendo as dificuldades que a classificação coloca, por divergência de critérios ou por ineficácia ou incompletude de alguns deles, mesmo assim Teofrasto defende esta metodologia como a mais correcta (1.3.1); o resultado que almeja, após a observação das plantas e suas partes, é poder compará-las e, a partir daí, estabelecer grupos. Desautels ${ }^{8}$ sublinha a importância e frequência com que Teofrasto usa a expressão 'considerar em termos gerais', talvez desde logo uma salvaguarda para rentabilizar princípios e critérios, torneando a sua falibilidade no particular. O resultado produzido é, em concomitância, uma visão de conjunto das plantas, acrescida de noçôes de base sobre os problemas gerais que estes seres implicam.

6 Suzanne Amigues, Théophaste. Recherches sur les plantes. Paris, Les Belles Lettres, 2010, p. 4.

7 Jacques Desautels, "La classification des végétaux dans la Recherche des plantes de Théophraste d'Erésos", Phoenix 42.3 (1988), pp. 231-232.

8 Jacques Desautels, "La classification ...", op. cit., p. 224 n. 16. 
A metodologia comparativa exige o estabelecimento de critérios de distinção; à semelhança dos estabelecidos por Aristóteles em $H A$ 487a 11-12 - 'As diferenças entre os animais dizem respeito ao seu modo de vida, actividade, carácter e partes que os constituem’ - também Teofrasto (1.1) enumera, como factores a considerar neste caso, 'as partes, as qualidades, a reprodução e as fases da vida'; e tem o cuidado de excluir 'o carácter e as actividades' e de justificar essa opção com as diferenças que distinguem plantas e animais; embora sendo todos seres vivos, os factores de distinção impóem à partida diferenças radicais.

Além do critério de semelhança e diferença, Teofrasto recupera, da ciência feita para os animais, o de analogia. Lembremos a definição, acrescida de exemplos, que dele dá Aristóteles (HA 645b 6-8): 'Por analogia entendo que, por exemplo, uns tantos animais tenham pulmão e outros não; mas que estes últimos, em contrapartida, tenham um outro órgão correspondente; ou ainda: uns têm sangue e outros um líquido análogo, com a mesma função que aquele desempenha nos sanguíneos' (cf. HA 486b 17 sqq., PA 644a 18). Claramente a analogia pode dar também um contributo útil para o propósito de fundo em Teofrasto, o da classificação das plantas.

Estabelecidos os factores relevantes para a caracterização das plantas, há que hierarquizá-los, do ponto de vista pragmático, fazendo avultar aqueles que se podem abordar por simples observação e que portanto surgem, ao estudioso, como mais imediatos e menos complexos. Esta verificação coloca as 'partes', referidas em primeiro lugar, como um elemento a merecer, pela sua complexidade, um tratamento longo e destacado. Naturalmente o tratado aristotélico das Partes dos animais tem, com esta preocupação, um diálogo próximo.

A objectividade que se exige dos factores utilizados na determinação de semelhanças, diferenças e analogias cria, no que diz respeito às partes das plantas, um problema metodológico de base; a questão resulta, por um lado, da variedade que lhes é própria, criando, do ponto de vista metodológico, alguma instabilidade; mas dada a importância que têm na caracterização das plantas, impóem-se como um factor prioritário e tornam outros aspectos — as qualidades, a reprodução e o modo de vida —, porque mais visíveis ou mais simples, secundários. Assim, antes de se partir para a classificação segura das plantas, há que clarificar o que se pode ou não considerar 'partes' e estabelecer uma nomenclatura técnica correspondente.

É interessante apreciar as dificuldades colocadas pela definição de uma nomenclatura técnica e as soluções usadas para a construção de um vocabulário científico. Desautels ${ }^{9}$ não hesita em considerar a insegurança terminológica 'como uma das maiores lacunas de Teofrasto', 'que o impediu de atingir um certo nível de ciência ou, pelo menos, de estabelecer entre os seres distinçôes válidas na perspectiva moderna'; talvez haja nesta reprovação do estudioso francês

9 Jacques Desautels, "La classification ...", op. cit., p. 238. 
algum exagero, ou desconhecimento do percurso moroso que a análise científica trilha em diálogo com a língua que lhe dá expressão.

O chamado 'senso comum' foi para Teofrasto, como antes para Aristóteles, uma fonte importante de informações e de soluçôes terminológicas; a consulta de agentes comuns — jardineiros e médicos, por exemplo, uns e outros, por motivos diferentes, bons conhecedores das plantas - forneceu-lhe uma visão concreta e uma designação, buscada na linguagem quotidiana, para as plantas, sua estrutura e grupos em que se dividem. Também aqui o confronto com as soluçóes encontradas pela biologia pôde servir de modelo e, de uma forma que se poderá dizer 'analógica', fornecer respostas. É o caso das 'fibras' e 'veias' nas plantas, que não chegam a ter uma designação específica, mas 'por semelhança, recebem as das partes correspondentes nos animais' (1.2.3, cf. 1.2.5). Igual estratégia é usada por outros fisiólogos que se viram a braços com o mesmo problema (1.2.6): 'A medula é o miolo da madeira e vem em terceiro lugar a contar da casca, como nos ossos a medula. Há quem lhe chame 'coração', outros 'coração da madeira'. É curioso registar o recurso a uma nomenclatura bem assente para situaçôes equivalentes nos animais, com o acrescento de uma precisão que assinale a semelhança e a novidade de aplicação ('coração da madeira', por exemplo). Teofrasto parece não hesitar, também nesta perspectiva, em recuperar uma nomenclatura que se tinha tornado corrente entre outros autores dedicados a especulaçóes semelhantes.

A abordagem das partes das plantas reparte-se em várias perspectivas: além da definição do que seja 'parte' e do estabelecimento de uma nomenclatura adequada, impóe-se fazer a caraterização de cada uma dessas partes e da sua finalidade. A definição de 'parte' cita-se como uma primeira exigência (1.2): 'É algo inerente à natureza específica de qualquer planta e parece estar sempre presente, quer em termos absolutos, quer quando aparece (à semelhança do que, nos animais, se desenvolve mais tarde)'. Por 'estar sempre presente' deve entender-se como permanente em todas as plantas do mesmo grupo. Não estamos muito longe do que Aristóteles entende por partes, referindo-se aos animais; a 'partes' é por ele dado um sentido abrangente, que inclui tecidos, órgãos, membros e, de um modo geral, os elementos constitutivos de todos os grupos de animais.

Este aspecto fulcral da 'permanência' que, nos animais, era adequado, coloca, no caso das plantas, dificuldades manifestas. É que há elementos na planta (flor, folha, fruto) que são de uma relevância incontestável, e no entanto têm uma duração limitada a um ano e sempre renovável. Variação e caducidade tornam a definição de 'parte' metodologicamente difícil e em conflito com a que, se aplicada aos animais, funciona. Uma tentação poderia ser a de excluir estes elementos como 'partes', pelos seus aspectos de incompatibilidade com questôes de base nessa definição; e, no entanto, a importância dos elementos referidos, 'que constituem a plenitude e a fisionomia das plantas', não pode ser eliminada sem grave prejuízo para o propósito científico em causa. De resto a finalidade - que é um critério essencial na definição de 'parte' 
- implica a sua inclusão: 'Porque qualquer planta se torna bela e parece atingir, ou melhor, atinge de facto, a sua plenitude quando rebenta, floresce ou frutifica'.

Verificada a inconveniência de ir pela exclusão deste factor, Teofrasto integra-o na sua abordagem e passa então a procurar uma esquematização geral da própria parte; nesse sentido, diferentes critérios podem ser adoptados. Dividi-las em internas e externas estabelece uma dicotomia de base, a que se anexa uma estratégia de estudo conforme com as exigências que tal divisão acarreta: para o conhecimento das partes exteriores basta a simples observação; para o das internas existe, como para os animais, a dissecção (cf. HA 503b 23-25, 531b — 532a). Junta-se-lhe uma segunda perspectiva, a da abrangência que uma parte pode ter dentro do universo das plantas: se é comum a todas, se particular a um determinado grupo apenas; e, num ou noutro caso, se apresenta semelhanças ou diferenças — de acordo com um critério de excesso ou defeito (cf. HA 486b) — e se existe na mesma posição ou noutra (1.6-7) — problema que se coloca em relação aos frutos, folhas e rebentos.

Só depois de estabelecidos estes critérios gerais de identificação e de comparação, se pode especificar cada uma das partes e passar à sua caracterização. Ao leitor atento do tratado não passarão despercebidas algumas incongruências ou imperfeições metodológicas; além da complexidade sempre assinalada do objecto de estudo, a natureza do tratado, como repositório de um conhecimento a divulgar oralmente em espaço de aula, implica um registo mais ou menos condicionado e uma actualização progressiva, responsável por muitos desajustes.

As partes que, certamente de acordo com a sua função, se podem considerar mais importantes, como também comuns a um maior número de plantas e tendencialmente perenes, são então referidas: raiz, caule, ramo e rebento; a que se acrescentam as que se renovam cada ano e contribuem para a sua reprodução: folhas, flores e fruto. A raiz pode desempenhar, no conjunto, um papel destacado; do mesmo modo que Aristóteles define a boca como o órgão mais relevante do ser vivo, que lhe permite alimentar-se e nutrir-se, Teofrasto faz da raiz, nas plantas, o seu equivalente (1.1.9), dentro do conceito aristotélico (cf. PA 650a) de que 'a terra é o estômago dos animais'.

As árvores, sendo as espécies a que estes elementos essencialmente correspondem, podem considerar-se paradigmáticas na classificação que se pretende esboçar (1.1.11). Tomadas como modelo, é a partir delas que, demarcando diferenças (abundância ou carência, densidade ou rarefacção, por exemplo), se pode caracterizar melhor as restantes plantas; no reino vegetal, parece caber às árvores o papel que, entre os animais, cabe ao Homem, como o mais bem conhecido e mais perfeito de todos os seres dessa espécie ${ }^{10}$. Esta é uma metodologia que obedece

10 Também ARISTóteles coloca no centro do seu projecto um primeiro caso individual, e esse é o ser humano, sobre o qual um melhor conhecimento está garantido pela própria familiaridade que dele aproxima o cientista (491a 23). E se preferimos o animal que melhor conhecemos, dele se exploram também, em primeiro lugar, 'as partes mais importantes, que compõem o corpo na sua totalidade' (491a 27-28). 
a um enunciado prático (1.2.3): 'Como se deve avançar do que é conhecido para chegar ao desconhecido e mais conhecido é o que é maior ou mais patente aos nossos sentidos, é óbvio que se deve tratar desses assuntos segundo essa metodologia'11. Uma lógica de paralelismo permitirá, a partir do que é conhecido e perceptível, especular sobre o desconhecido e menos acessível ${ }^{12}$.

Identificadas as várias partes, o estudo das plantas pode então processar-se tendo em consideração dois aspectos: o estabelecimento de diferenças gerais entre as plantas no que se refere às partes essenciais; e a consideração das potencialidades e razão da existência ou finalidade de cada uma dessas partes. A partir das árvores, não só se pode estabelecer diferenças em relação a cada planta, como demarcar conjuntos de plantas; ou seja, de uma abordagem analítica encara-se a necessidade de promover sínteses, de modo a criar grupos. Estamos realmente a caminho de uma classificação.

Tidas as árvores como paradigma, devido às partes que nelas são claramente visíveis, Teofrasto ensaia uma primeira classificação de plantas em quatro grandes grupos: 'árvores, arbustos, subarbustos e ervas' (1.3.1). A execução prática desta primeira grande classificação — que assenta apenas em aspectos exteriores, como o tamanho e a ausência ou presença de certas partes — irá denunciar debilidades, que recusam ou contestam a virtude dos critérios dicotómicos estritos (1.3.2): 'Em certos casos pode parecer que a nossa classificação sofre alteraçóes; e, em contrapartida, há plantas que, em cultivo, se tornam diferentes e parecem mudar de natureza'. A complexidade vai-se tornando patente, pela intromissão de vários factores no rigor básico das diferenças entre grupos. Factores exteriores às próprias plantas condicionam-nas e podem criar alteraçôes profundas nas suas características. É o caso das condições de manutenção, que distinguem de modo profundo plantas de cultivo e as suas correspondentes em estado selvagem; ou naturalmente o habitat (por exemplo a distinção entre plantas terrestres e aquáticas) e as condiçôes geográficas ou climatéricas ${ }^{13}$. Apesar dos imprevistos que estes outros factores acarretam, há que tê-los em consideração na sua 'permanência', na medida em que a vida de nenhuma planta lhes é alheia.

11 Cf. HA 495b 14-16, 506a 7-8, 513a 33-36, 515a 19-23.

12 Como fontes para a sua investigação, Teofrasto terá privilegiado a observação directa, processada em deslocações ou estadias mais ou menos prolongadas por várias regiões (a ilha de Lesbos, a Tróade, a Macedónia e a Ática, Arcádia e Egipto), como também a leitura de informações produzidas por outros autores que, por diversas razões, se interessaram por questões relacionadas com vegetais, desde logo os historiadores e geógrafos, relatores de paisagens estranhas ou desconhecidas; já antes deles Homero e as artes plásticas foram responsáveis pela menção de um número elevado de espécies vegetais; vide Arthur Stanley PEASE, "A sketch of the development of ancient botany", Phoenix 6.2 (1952), pp. 44-51. A partir de todos estes elementos, o fisiólogo elabora uma reflexão, depurando os usos tradicionais e estabelecendo uma verdadeira problemática.

13 S. Amigues, Théophraste. Recherches ... , op. cit., p. xv, não hesita em afirmar que a transplantação de espécies selvagens para jardins ou o cultivo de plantas exóticas, provindas de outros habitats, constituía um tipo de experiência corrente. 
Assim, a observação das plantas, tal como a dos animais, permite ao naturalista reconhecer, no concreto, as consequências dos grandes princípios que regem a actuação da natureza, no que é a constituiçáo dos seres com vista a uma funcionalidade harmoniosa, na relação interna entre as partes que os constituem e, pontualmente, no convívio entre espécies ou de cada uma com o habitat que a cerca. Há que estabelecer critérios que permitam a transição de um conhecimento geral ou indeterminado para outro, circunscrito e específico às situaçóes concretas.

E é talvez esta a exigência que trava, de certa forma, o alcance do tratado de Teofrasto dedicado à Botânica. O grau de sistematização conseguido é modesto, o efeito final aproxima-se mais de um relato de diferentes espécies do que de uma classificação, o desrespeito pela própria proposta metodológica é patente em certos momentos, a hierarquização das plantas carece de rigor. Mesmo assim, Teofrasto abre caminhos, no estabelecimento de parentescos entre as espécies, de grandes divisóes e agrupamentos, que se tornam remissão necessária para os grandes passos dados pela Botânica no futuro.

\section{BIBLIOGRAFIA}

Amigues, Suzanne, Théophraste. Recherches sur les plantes. Paris, Les Belles Lettres, 2010.

Desautels, Jacques, "La classification des végétaux dans la Recherche des plantes de Théophraste d' Erésos", Phoenix 42.3 (1988), pp. 231-232.

Kullmann, Wolfgang, “Aristotle as a natural scientist”, Acta Classica 34 (1991), pp. 137-150.

Pease, Arthur Stanley, "A sketch of the development of ancient botany", Phoenix 6.2 (1952), pp. 44-51.

Thanos, Costas A., "Aristotle and Theophrastus on plant-animal interactions", in Margarita Arianoutsou, and Richard H. Groves, Plant-Animal Interactions in Mediterranean-Type Ecosystems. Dordrecht/Boston/ London, Kluwer Academic Publishers, 1994, pp. 3-11. 
A partir dos alvores do século XVI, a matéria médica torna-se indiscutivelmente um tema de primeira grandeza entre os membros da República das Letras, objecto de estudo e de controvérsia entre os mais notáveis humanistas europeus, em particular entre os cultores da arte médica. Entre os autores em destaque neste volume encontram-se, à cabeça, os nomes de Amato Lusitano, Garcia de Orta e Nicolás Monardes, famosos pelos contributos valiosos que deram para o conhecimento do mundo natural. 0 volume encontra-se dividido em duas partes: a primeira, subordinada ao título "Humanismo e Ciência", alberga os estudos que versam sobre todos os autores estudados, à excepção de Amato Lusitano; a segunda está reservada a um conjunto de trabalhos dedicados exclusivamente ao médico albicastrense, cuja autoria se fica a dever, em boa parte, aos membros da equipa do projecto de I\&D "Dioscórides e o Humanismo Português: os Comentários de Amato Lusitano", tomando, por isso, 0 seu próprio título. Nesta segunda parte, oferece-se, desde já, aos leitores uma amostra significativa do trabalho desenvolvido no âmbito do projecto e que culminará, assim se espera, na edição e tradução integral para língua portuguesa das quatro obras previstas de Dioscórides, Amato Lusitano e Pietro Andrea Mattioli. 
